Research Article

\title{
The Designing of Magnetic-Driven Micromirror for Portable FTIRs
}

\author{
Shaoxi Wang $\mathbb{D}^{1,2}$ and Xuan Yuan ${ }^{2}$ \\ ${ }^{1}$ School of Software \& Microelectronics, Northwestern Polytechnical University, Xi'an, Shaanxi, China \\ ${ }^{2}$ School of Mechanical Engineering, Ryerson University, Toronto, ON, Canada \\ Correspondence should be addressed to Shaoxi Wang; shxwang@nwpu.edu.cn
}

Received 26 September 2017; Revised 3 January 2018; Accepted 16 January 2018; Published 21 February 2018

Academic Editor: Paolo Bruschi

Copyright ( $\odot 2018$ Shaoxi Wang and Xuan Yuan. This is an open access article distributed under the Creative Commons Attribution License, which permits unrestricted use, distribution, and reproduction in any medium, provided the original work is properly cited.

\begin{abstract}
Fourier transform infrared spectroscopy is a widely used instrument to analyze and test different materials including organic and inorganic. Most of current commercial Fourier transform infrared spectrometers are limited in miniaturization and scanning velocity by their macroscopic components. MEMS FTIR spectroscopy is one of the important applications of translational actuator-driven systems by using MEMS technology. The critical component in MEMS FTIRs is the large displacement translating micromirror and its actuator. The paper presents a large displacement and high-surface quality micromirror. The micromirror consists of a micromagnetic actuator and a micromirror plate. The mirror plate and the actuator are fabricated separately and bonded together afterwards, and its size is $3.6 \times 3.6 \mathrm{~mm}^{2}$ high-surface quality square mirror plate and a $1 \mathrm{~cm}^{2}$ moving part. The microactuator's moving part is fabricated using MetalMUMPS, and its fixed part includes a ring permanent magnet and a solenoid to realize a large displacement. The mirror plate is fabricated using polished silicon coated with metal layer with high-surface prototypes that are fabricated and experimentally tested. A maximum stroke of $400 \mu \mathrm{m}$ has been achieved in pull-in whereas only $140 \mu \mathrm{m}$ stroke have been measured for a 4 to 5 -volt DC-controlled displacement, and the resonance frequency is $10 \mathrm{~Hz}$.
\end{abstract}

\section{Introduction}

Fourier transform infrared spectroscopy (FTIRs) is a widely used instrument to analyze and test different materials including organic and inorganic [1]. As a mainstream method of infrared spectrometer, FTIRs is the most popular technology because of its high resolution, high signal-tonoise ratio, and high stability. However, the complexity and development of many applications require analysis instrument to achieve rapid detection of materials on the spot such as geological exploration. With regard to this, the current commercial Fourier transform infrared spectrometers have lots of disadvantages, such as large size, usually static, poor portability, and being operated by qualified personnel. The FTIRs is based on a two beam Michelson interferometers. Most of them are limited in miniaturization and scanning velocity by their macroscopic components.
With the development of microelectromechanical system (MEMS), the MEMS micromirror becomes steady and low cost, which makes the miniaturization of instruments become possible. A new class of miniaturized, robust, high speed, and cost-efficient FTIR systems can be addressed.

To achieve the miniaturized FTIRs, Sandner et al. [2] gave actuators for optical path length modulation for miniaturized FTIRs, in which the mirror thickness is limited resulting to weakness surface flatness. Also, Sandner et al. [3] presented MOEMS based FTIRs, which has translational out-of-plane oscillation at $500 \mathrm{~Hz}$ with large stroke of up to $1 \mathrm{~mm}$. Although the amplitude is large enough, the FTIRs are resonant driven. Warashina et al. [4] achieved a very small size FTIRs with system on chip designing. However, the parameters of FTIRs such as resolution (which is $25 \mathrm{~cm}^{-1}$ ) and SNR (which is greater than $35 \mathrm{~dB}$ ) are not good enough. 
MEMS FTIR spectroscopy is one of the important applications of translational actuator-driven systems by using MEMS technology. The sensing unit can be built in a small size with high reliability and low fabrication cost. The critical component in MEMS FTIRs is the large displacement translating micromirror. To improve the resolution, high-surface quality and no-resonant displacement of a few hundred micrometers are required for the micromirror [5]. It is still a challenge for MEMS micromirrors to reach a high-static displacement with high-surface quality.

As so far, many works about several miniaturized MEMS devices for FTIRs have been reported. Electrostatic silicon on insulator MEMS with in-plane translator mirror is limited by its thickness to small mirror size [6-9] such as $0.5 \mathrm{~mm}$ in diameter. Kung et al. and Antila described vertical out-ofplane MEMS mirrors with an electrostatic plate capacitor drive $[10,11]$. Their results are only $65 \mu \mathrm{m}$ amplitude and $6 \mu \mathrm{m}$ for a $6 \mathrm{~mm}$ translator mirror. Drabe et al. [12], Ataman et al. [13], and Ferhanoglu et al. [14] have used resonant inplane comb drives. Wang et al. [15, 16] and Han et al. [17] are based on nonresonant electrothermal actuation. These translatory MOEMS devices could be used for instance to adjust an optical path length/optical path difference, something which is of interest for a range of applications, including confocal microscopy, optical coherence tomography, and also for FTIR spectroscopy.

In this paper, a large displacement and high-surface quality micromirror are presented. The micromirror consists of a micromagnetic actuator and a micromirror plate. The mirror plate and the actuator are fabricated separately and bonded together afterwards. The microactuator's moving part is fabricated using MetalMUMPS, and its fixed part includes a ring permanent magnet and a solenoid to realize a large displacement. The mirror plate is fabricated using polished silicon coated with metal layer with a high-surface quality. Prototypes are fabricated and experimentally tested. A maximum stroke of $400 \mu \mathrm{m}$ has been achieved in pull-in whereas only $140 \mu \mathrm{m}$ stroke have been measured for a DC-controlled displacement.

\section{Device Design}

A MEMS magnetic actuator is a device that uses the microelectromechanical systems (MEMS) to convert an electric current into a mechanical output by employing the wellknown Lorentz force equation or the theory of magnetism. The designing of micromirror is given in Figure 1, which includes a mirror plate and a micromagnetic actuator. The microactuator and the mirror plate are fabricated separately and bonded together after they are fabricated. The first part is fabricated using polished silicon wafer and coated with thin metal layer as shown in Figure 1(a). The thickness of the mirror plate ranges from several tens to several hundreds of micrometers according to the applications. The aperture of the mirror plate is from $1 \mathrm{~mm}$ to several $\mathrm{mm}$. Therefore, a high-surface quality can be obtained including high flatness and good roughness.

The moving part of the actuator moves down when a current is applied to the solenoid, and if no current applied to the solenoid, the moving part of the actuator is attracted up by the ring permanent magnet. The current in the solenoid controls the downward displacement of the actuator along with the bonded mirror plate until the displacement reaches the "pull-in" range.

The actuator includes a moving part and fixed parts. The moving part has four trapezoidal nickel plates and a central structure for bonding the mirror plate. The four trapezoidal nickel plates are connected to the central structure through connection springs and supported by anchors through anchoring springs as shown in Figure 1(b). The fixed parts include one ring permanent magnet above the moving part of the actuator and a solenoid under it, as shown in Figure 1(c). The moving part of the actuator is fabricated using MetalMUMPS and is made of $20 \mu \mathrm{m}$ thick nickel. The mirror plate is bonded to the actuator's moving part in the area of the central structure. The mirror plate is $6 \mathrm{~mm}$ in diameter and $350 \mu \mathrm{m}$ in thickness. The upper edge of trapezoidal plate is $3 \mathrm{~mm}$ and the lower edge is $6 \mathrm{~mm}$, whose height is $2 \mathrm{~mm}$. The spring in the mirror is $0.8 \mathrm{~mm} \times 0.8 \mathrm{~mm}$. The magnet is $1.5 \mathrm{~cm}$ in diameter and $0.5 \mathrm{~cm}$ in height. Figure $1(\mathrm{~d})$ shows the assembled micromirror. Bonding information will be given in following section.

Basing on the mentioned working principle above, the micromirror is designed as below.

2.1. Stress Verification. In order to verify if the maximum stress in the actuator is less than the yield strength, the actuator is simulated using Coventor. The simulation result shows a translation of $710 \mu \mathrm{m}$ that can be achieved with the maximum stress smaller than the yield strength which is $400 \mathrm{Mpa}$, as shown in Figure 2.

2.2. Bonding the Mirror Plate and the Actuator. Bonding of the mirror plate and the actuator is the critical part of this micromirror, which faces following challenges: (1) The actuator moving part is as thick as 20 micrometers. It is very fragile and easy to induce plastic deformation; (2) a small amount of adhesive that leaked from the backside of the mirror plate will stick the mirror plate, moving part, and substrate together. The adhesive leakage could occur during the bonding operation and the drying process. To solve these problems, a lot of iterations for tuning the bonding process and designing the bonding structure were conducted till the bonding challenges are completely addressed. All detail information about bonding process can be found in [18].

2.3. Displacement Measurement Structure. A measurement process and a setup are developed as illustrated in Figure 3. A laser beam parallel to the table shoots to the mirror plate, which is perpendicular to the table, and the reflected beam is on the PSD (position sensor detector). The PSD can measure the $x$ and $y$ positions of the laser dot. By measuring the moving distance of the laser dot on PSD when driving the actuator, the translation of the micromirror can be calculated according to the calibration which records the reflected laser dot moving distance on PSD when manually translating the micromirror, which sits on a fine translation stage with moving direction perpendicular to the mirror plate surface. 


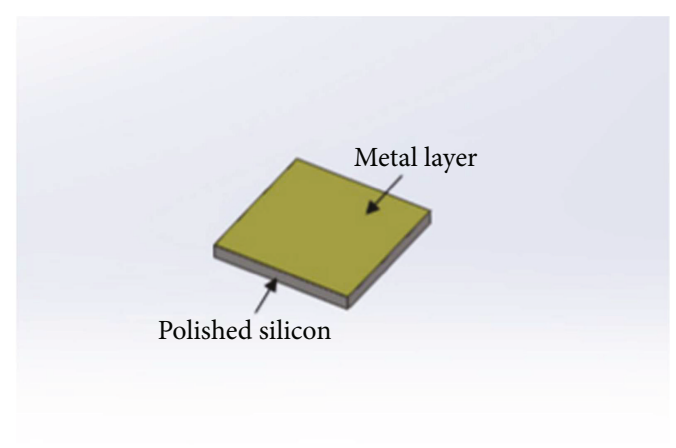

(a) Mirror plate

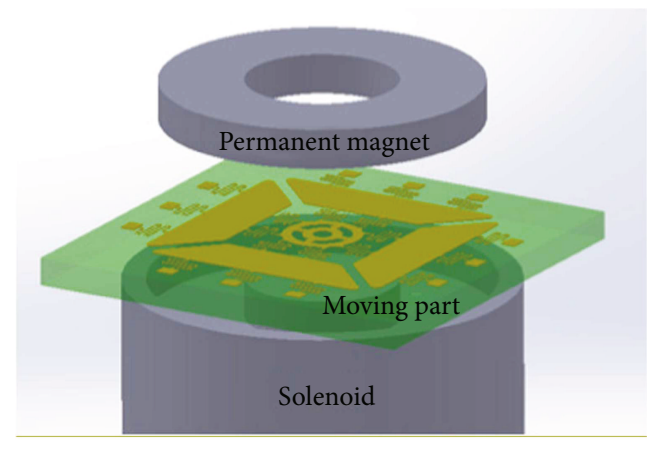

(c) Moving and fixed parts

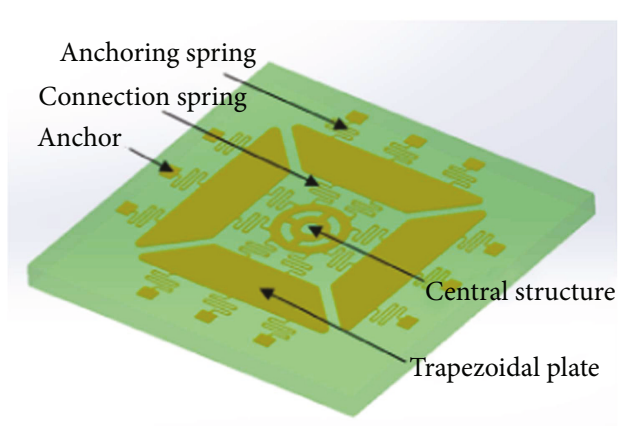

(b) Actuator moving part

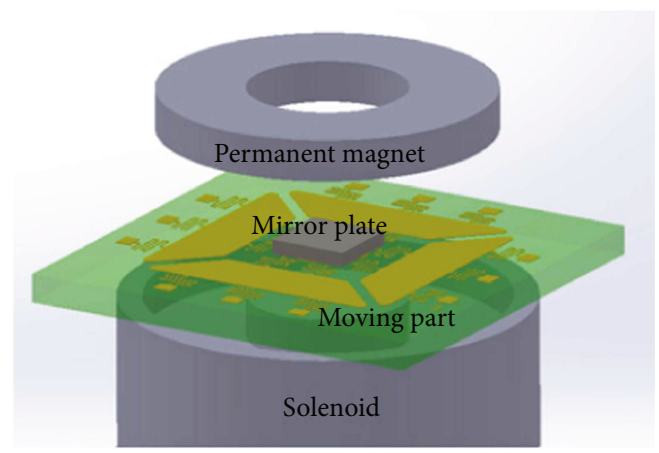

(d) Actuator and the mirror plate

Figure 1: Concept of the new micromirror.

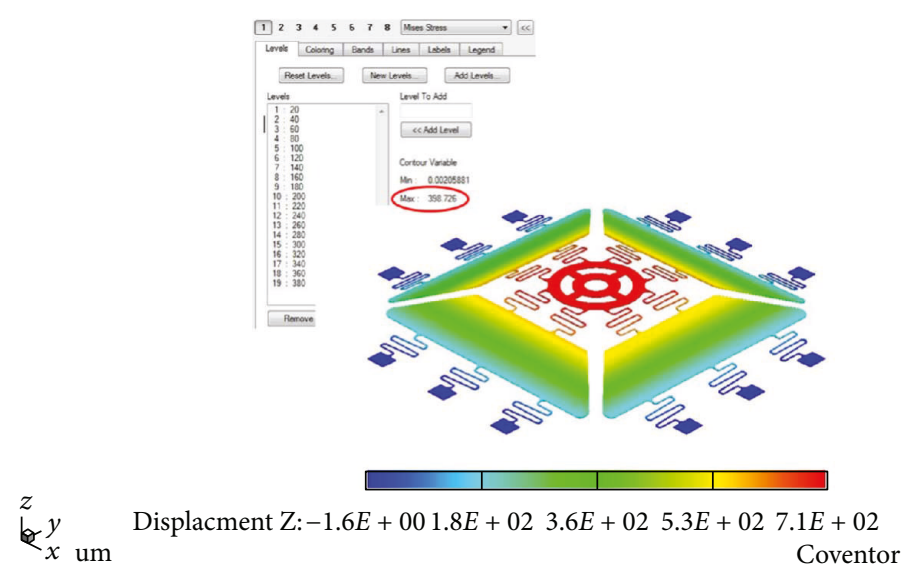

FIgURE 2: Stress simulation using CoventorWare.

In order to separate the translation from the rotation, the following steps are performed in the measurement. Rotating the micromirror around the $z$-axis until the trajectory of reflection beam is parallel to the $x$-axis. Now, the rotating axis is perpendicular to the table along $y$-axis. By rotating the micromirror $90^{\circ}$ around the $z$-axis, its rotation axis will be parallel to the table, so the translation and rotation are separated in $x$-axis and $y$-axis, respectively.

Using above method, the tilting of the micromirror can be found and compensated. However, it is based on an assumption that the micromirror is set perpendicular to the table, which is difficult to guarantee in the real experiment environment. To avoid the error caused by it, the micromirror is rotated $180^{\circ}$ after the first trajectory of reflection beam that is parallel to the $x$-axis is found and the second trajectory can be derived using the same way. Because the angle between the micromirror and the table is caused during the setup, its effect can be eliminated by taking a median of these 2 displacements, and then the real translation displacement can be obtained.

\section{System Experiments}

The prototype of the actuator moving part is fabricated using MetalMUMPs, as shown in Figure 4. Figure 4(a) shows the $3.6 \times 3.6 \mathrm{~mm}^{2}$ high-surface quality square mirror plate and a $1 \mathrm{~cm}^{2}$ moving part. Figure 4(b) shows the mirror plate bonded to central structure of the moving part. 


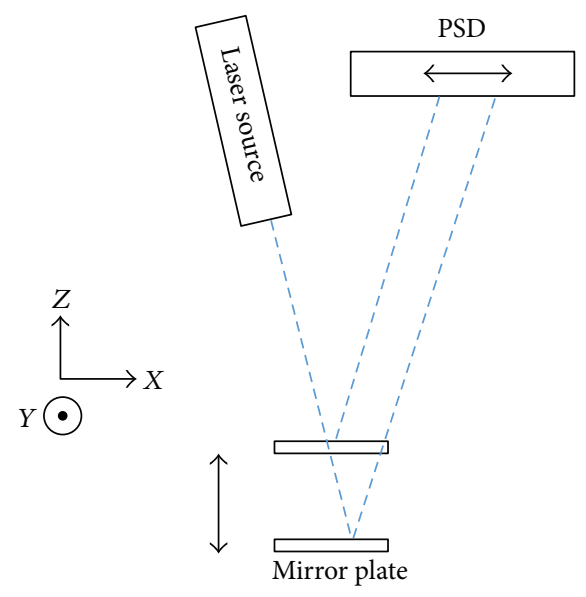

(a) Micromirror translates along the $z$-axis (2D)

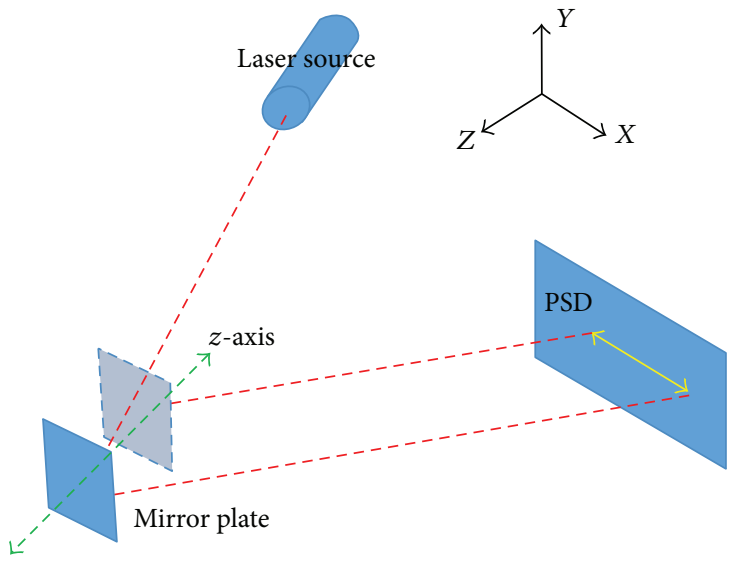

(b) Micromirror translates along the $z$-axis (3D)

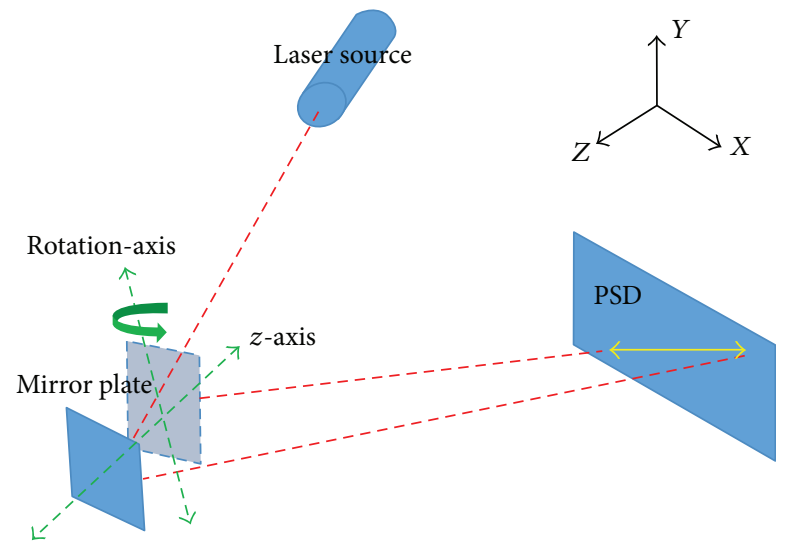

(c) Micromirror in an angle with the $x$-axis

FIgURe 3: Concept of displacement measurement.

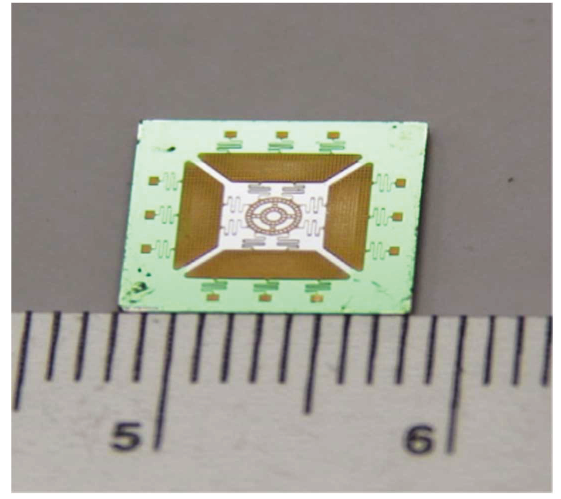

(a) Mirror plate and actuator

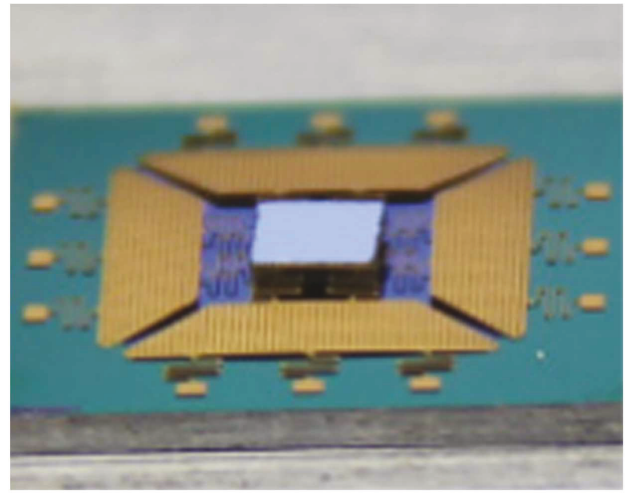

(b) Mirror plate bonded on the moving part

Figure 4: The final prototype of the micromirror.

The displacement measurement experiment is performed using the equipment setup in Figure 5. The assembly structure for displacement testing includes a high-precision rotation platform, a translation stage, a magnet holder, a chip holder, and a solenoid holder. A ring-shaped permanent magnet, which has $8 \mathrm{~mm}$ outer diameter and $3.8 \mathrm{~mm}$ inner diameter, is used to pull the moving part up. And a $0.5 \mathrm{~mm}$ thick gasket is used to increase the distance between the permanent magnet and moving part to $3 \mathrm{~mm}$. The moving part is positioned on the chip holder and fixed by the powerful double-sided tape. After assembled, the assembly structure is mounted on a single-axis translation stage which is further mounted on a lab jack, so that the assembly structure can move in both horizontal and vertical directions. The laser source is placed on a right-angle clamp to ensure the laser beam is parallel to the table and a pinhole is used to reduce 


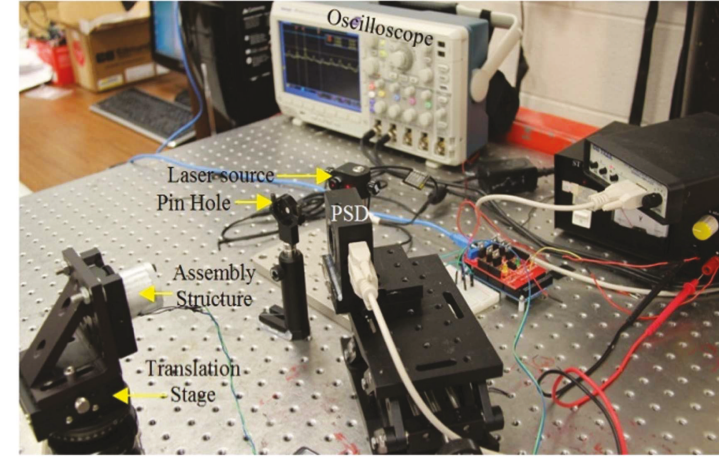

(a)

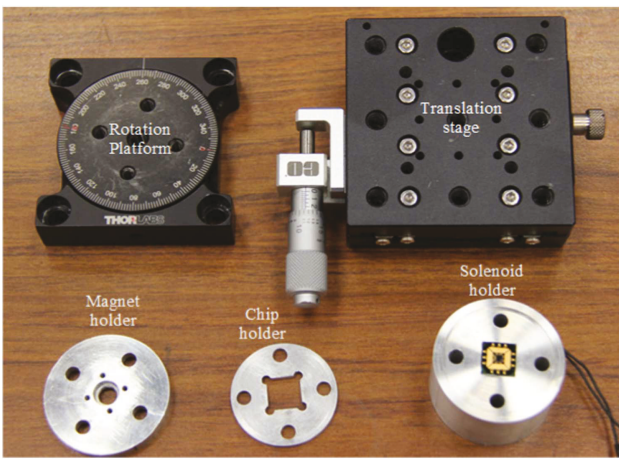

(b)

Figure 5: Displacement measurement experiment setup.

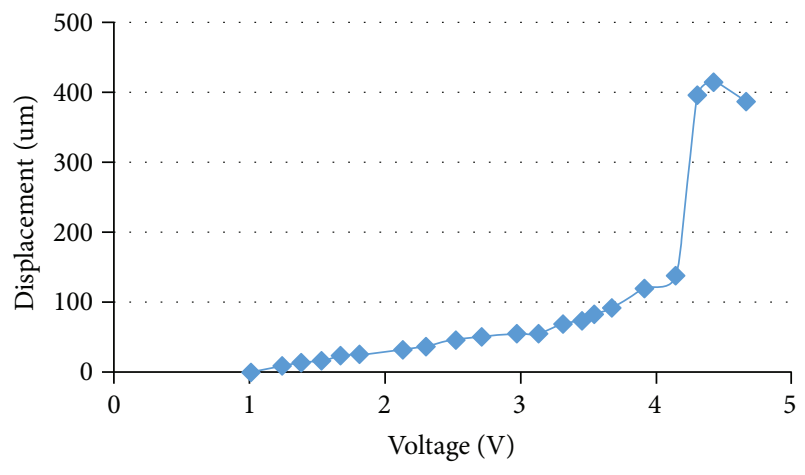

FIGURE 6: Displacement versus voltage.

the size of laser spot to within the mirror plate. A PSD is mounted on the lab jack to receive the reflected beam from the mirror plate. And an oscilloscope connected to the PSD shows the position of the laser spot on the PSD.

The test result in Figures 6 and 7 shows the micromirror can be pulled up about $400 \mu \mathrm{m}$ by the $8 \mathrm{~mm}$ ring-shaped permanent magnet. A pull-in phenomenon is found when the voltage applied on the solenoid is over $4 \mathrm{~V}$, where its current is $450 \mathrm{~mA}$. Then the solenoid attracts the actuator down to the substrate. The displacement can be controlled through adjusting the current in the solenoid adjustment when it is within $140 \mu \mathrm{m}$.

Moreover, the tilting angle of the micromirror is shown in Figure 8. From the figure, the tilting angle is $0.1^{\circ}-0.21^{\circ}$ based on the measurement of prototypes. The tilting is not good enough in fact for application. Future development should be worked on the concept proposed in this work, such as adopting rectangular plates for its structure.

Table 1 showed the results compared to reference $[2,18]$ which are typical results published. According to Table 1, the actuator design in this work can achieve the mirror plate with $3.6 \times 3.6 \mathrm{~mm}^{2}$ and $350 \mu \mathrm{m}$ in thickness according to the applications. Therefore, a high-surface quality can be obtained including high flatness and good roughness.

\section{Conclusion}

MEMS FTIR spectroscopy is one of the important applications of translational actuator-driven systems by using

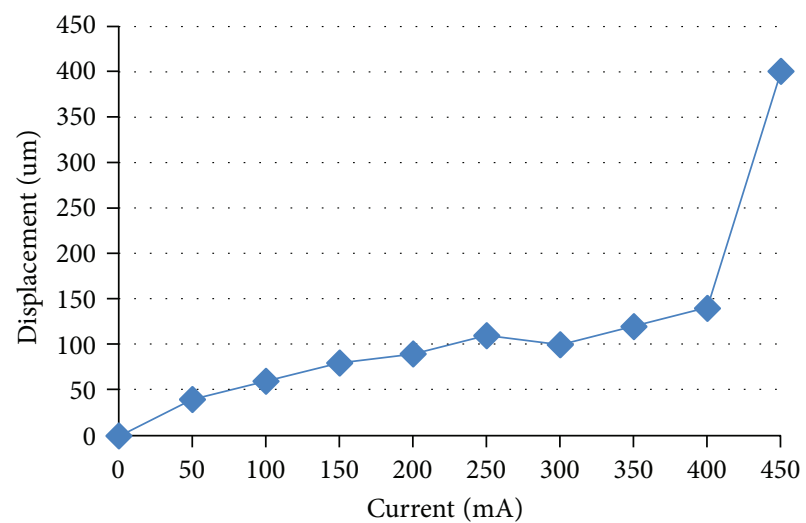

FIgURE 7: Displacement versus current.

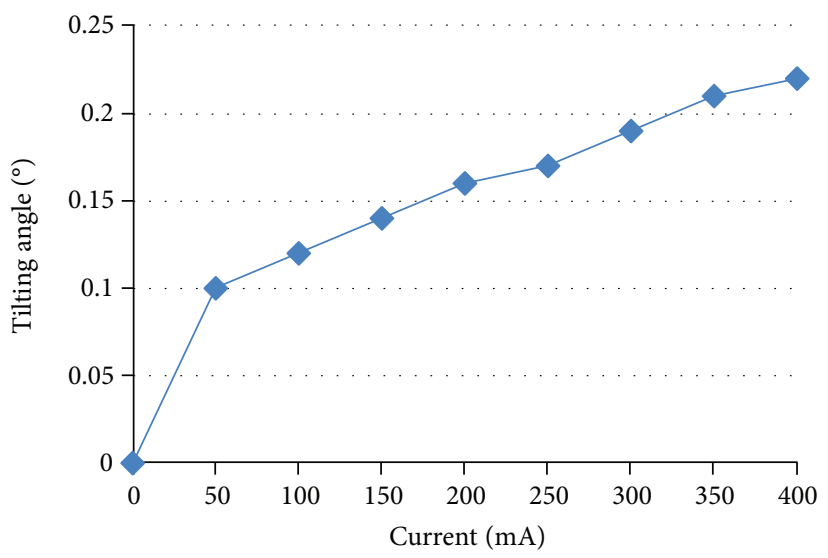

FIGURE 8: The tilting angle of the micromirror.

TABLE 1: The comparison of several results.

\begin{tabular}{lcc}
\hline & Mirror & Displacement \\
\hline$[2]$ & $5 \mathrm{~mm}($ diameter $)$ & $300 \mu \mathrm{m}$ \\
{$[18]$} & $2 \times 2 \mathrm{~mm}^{2}$ & $123 \mu \mathrm{m}$ \\
This work & $3.6 \times 3.6 \mathrm{~mm}^{2}$ & $400 \mu \mathrm{m}$ \\
\hline
\end{tabular}

MEMS technology. The sensing unit can be built in a small size with high reliability and low fabrication cost. The critical component in MEMS FTIRs is the large displacement-translating 
micromirror. To improve the resolution, high-surface quality and no-resonant displacement of a few hundred micrometers are required for the micromirror.

In this work, a novel micromirror for MEMS FTIRs is proposed, which includes the mirror plate with $3.6 \times 3.6 \mathrm{~mm}^{2}$ and $350 \mu \mathrm{m}$ in thickness. The micromirror can achieve large displacement and high reflectivity by fabricating the actuator and mirror plate separately. A bonding process and the bonding mechanism are developed to bond the mirror plate onto the moving part. A process is developed to measure the translation displacement of the micromirror. A maximum stroke of $400 \mu \mathrm{m}$ has been achieved in pull-in whereas only $140 \mu \mathrm{m}$ stroke have been measured for a DC-controlled displacement.

\section{Conflicts of Interest}

The authors declare that they have no conflicts of interest.

\section{Acknowledgments}

The work is supported by Science and Technology Development Program of Shaanxi Province (no. 2016GY091) and Natural Science Foundation of Shenzhen (no. JCYJ201604291531109 08).

\section{References}

[1] P. R. Griffiths and J. A. Haseth, Fourier Transform Infrared Spectrometry, Wiley, New York, 1986.

[2] T. Sandner, C. Drabe, H. Schenk, A. Kenda, and W. Scherf, "Translatory MEMS actuators for optical path length modulation in miniaturized Fourier-transform infrared spectrometers," Journal of Micro/Nanolithography, MEMS, and MOEMS, vol. 7, no. 2, article 021006, 2008.

[3] T. Sandner, T. Grasshoff, E. Gaumont, H. Schenk, and A. Kenda, "Translatory MOEMS actuator and system integration for miniaturized Fourier transform spectrometers," Journal of Micro/Nanolithography, MEMS, and MOEMS, vol. 13, no. 1, article $011115,2014$.

[4] Y. Warashina, T. Suzuki, K. Kasamori, R. Okumura, Y. Matsuo, and M. Takemura, "MEMS based miniature FTIR engine with built-in photodetector," in Proceedings Volume 8977, MOEMS and Miniaturized Systems XIII, SPIE MOEMSMEMS. International Society for Optics and Photonics, San Francisco, CA, USA, 2014.

[5] B. C. Smith, Fundamentals of Fourier Transform Infrared Spectroscopy, CRC Press, Boca Raton, 2nd edition, 2011.

[6] O. Manzardo, H. P. Herzig, C. R. Marxer, and N. F. de Rooij, "Miniaturized time scanning Fourier transform spectrometer based on silicon technology," Optics Letters, vol. 24, no. 23, pp. 1705-1707, 1999.

[7] O. Manzardo, R. Michaely, F. Schädelin et al., "Miniature lamellar grating interferometer based on silicon technology," Optics Letters, vol. 29, no. 13, pp. 1437-1439, 2004.

[8] K. Yu, D. Lee, U. Krishnamoorthy, N. Park, and O. Solgaard, "Micromachined Fourier transform spectrometer on silicon optical bench platform," in The 13th International Conference on Solid-State Sensors, Actuators and Microsystems, 2005. Digest of Technical Papers. TRANSDUCERS '05, vol. 2, pp. 1250-1254, Seoul, South Korea, June 2005.
[9] C. Ataman and H. Urey, "Compact Fourier transform spectrometers using FR4 platform," Sensors and Actuators A: Physical, vol. 151, no. 1, pp. 9-16, 2009.

[10] H. L. Kung, S. R. Bhalotra, J. D. Mansell, D. A. B. Miller, and J. S. Harris, "Standing-wave transform spectrometer based on integrated MEMS mirror and thin-film photodetector," IEEE Journal of Selected Topics in Quantum Electronics, vol. 8, no. 1, pp. 98-105, 2002.

[11] J. Antila, Micro-Electromechanical Mirror for Fourier Transform Interferometry, VTT Information Technology, 2003.

[12] C. Drabe, H. Schenk, K. U. Roscher, D. Kunze, and H. Lakner, "Accelerometer by means of a resonant micro actuator," Proceedings of SPIE, vol. 5344, pp. 124-133, 2004.

[13] C. Ataman, H. Urey, and A. Wolter, "A Fourier transform spectrometer using resonant vertical comb actuators," Journal of Micromechanics and Microengineering, vol. 16, no. 12, pp. 2516-2523, 2006.

[14] O. Ferhanoglu, H. R. Seren, S. Lüttjohann, and H. Urey, "Lamellar grating optimization for miniaturized Fourier transform spectrometers," Optics Express, vol. 17, no. 23, pp. 21289-21301, 2009.

[15] W. Wang, J. Chen, A. S. Zivkovic, C. Duan, and H. Xie, “A silicon based Fourier transform spectrometer base on an open-loop controlled electrothermal MEMS mirror," in 2015 Transducers - 2015 18th International Conference on SolidState Sensors, Actuators and Microsystems (TRANSDUCERS), pp. 212-215, Anchorage, AK, USA, June 2015.

[16] W. Wang, J. Chen, A. S. Zivkovic, Q. A. A. Tanguy, and H. Xie, "A compact Fourier transform spectrometer on a silicon optical bench with an electrothermal MEMS mirror," Journal of Microelectromechanical Systems, vol. 25, no. 2, pp. 347$355,2016$.

[17] F. Han, W. Wang, X. Zhang, and H. Xie, "Modeling and control of a large-stroke electrothermal MEMS mirror for Fourier transform microspectrometers," Journal of Microelectromechanical Systems, vol. 25, no. 4, pp. 750-760, 2016.

[18] Y. Xue and S. He, "Magnetic field assisted bonding technology for released micro actuator and mirror surface," Microsystem Technologies, vol. 23, no. 10, pp. 4941-4955, 2017. 


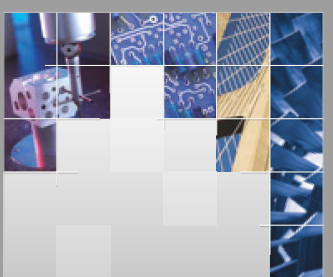

\section{Enfincering}
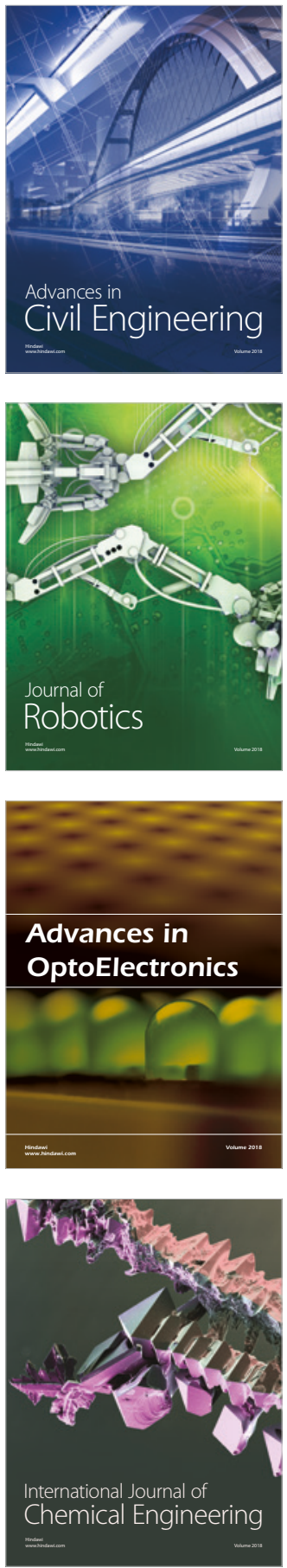

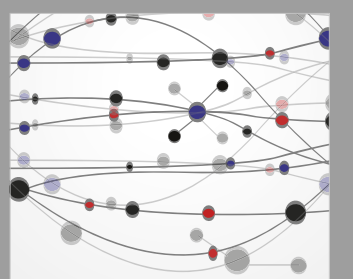

\section{Rotating \\ Machinery}

The Scientific World Journal

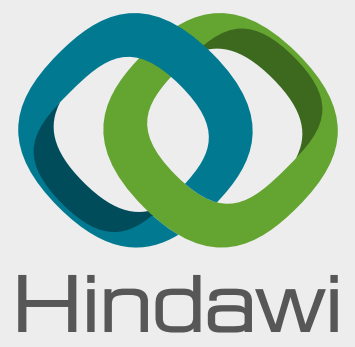

Submit your manuscripts at

www.hindawi.com
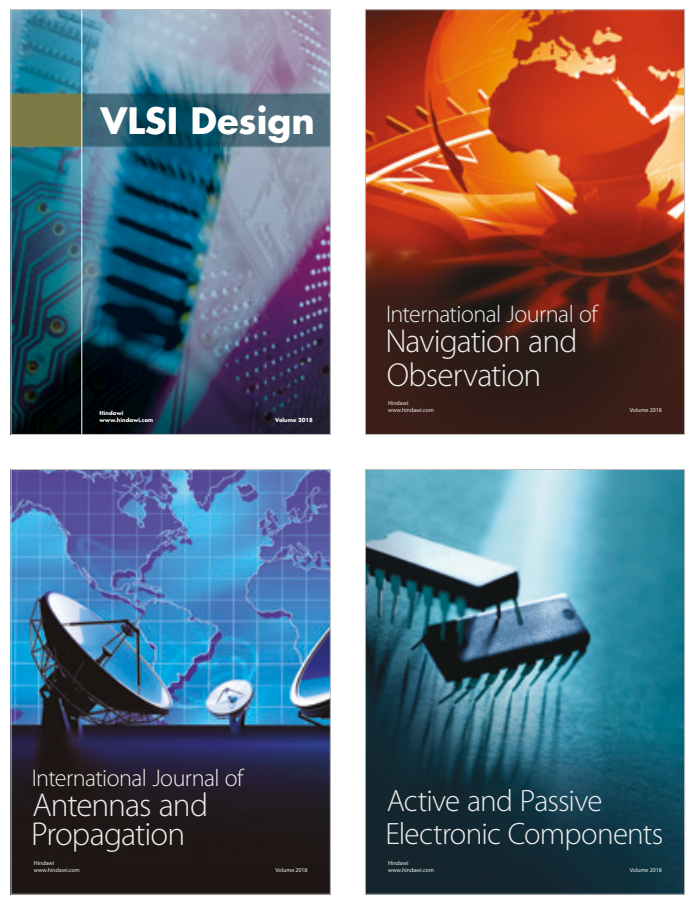
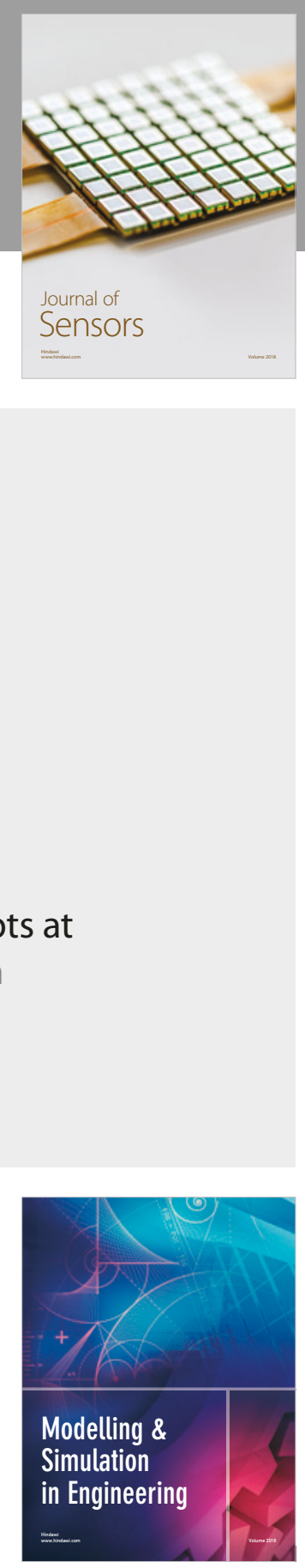

\section{Advances \\ Multimedia}
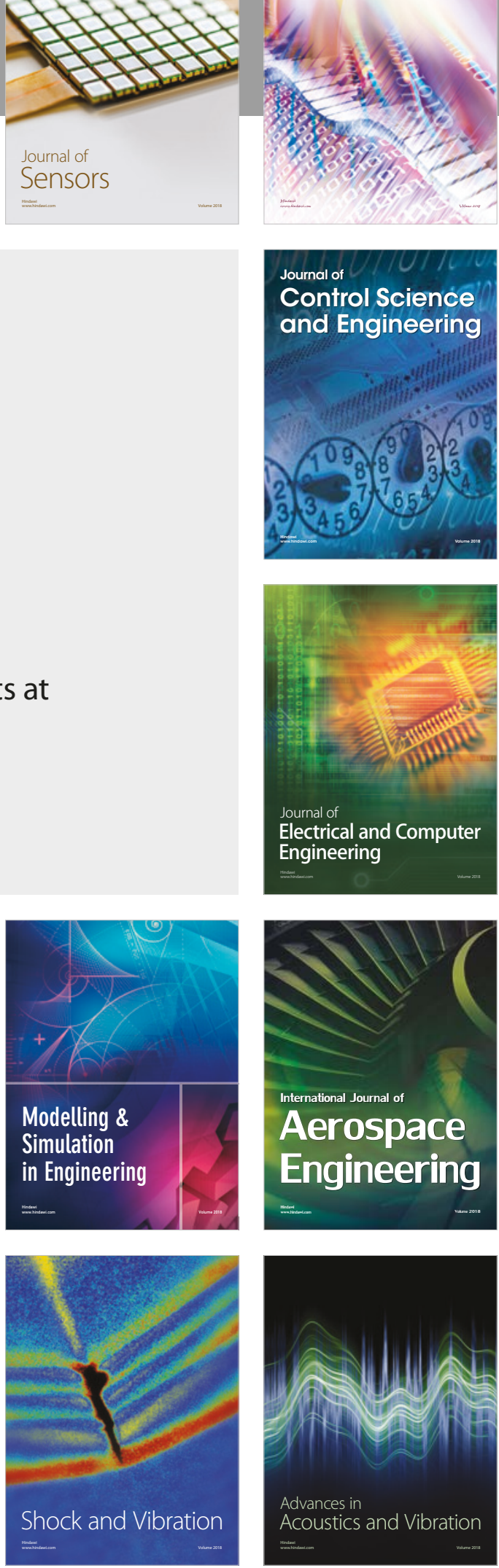